\title{
Pengaruh Pendidikan Kewirausahaan dan Motivasi Usaha terhadap Minat Berwirausaha (Studi pada Mahasiswa Fakultas Ekonomi Universitas Muhammadiyah Ponorogo)
}

\author{
Wira Bharata \\ Fakultas Ekonomi, Universitas Muhammadiyah Ponorogo, Indonesia \\ E-mail : wira.bharata@gmail.com
}

\begin{abstract}
The development of curricula and courses for entrepreneurship education has occurred since the early 80s. Academic institutions have worked hard in developing appropriate entrepreneurship education programs and small businesses. Although its history is relatively short, entrepreneurship education has become a teaching area that is widely recognized and recognized at universities and business schools. However, questions about the effectiveness of entrepreneurship education programs and how strategies are designed to maximize their effectiveness remain unanswered. The content and context of entrepreneurship education programs in various institutions, regions and countries can be different. This research was conducted at the Muhammadiyah Ponorogo University with the student population of Muhammadiyah Ponorogo University. The sampling technique used a systematic random sampling method, with a sample of 50 people. The data obtained was analyzed using the GSCA analysis tool. The results showed that Entrepreneurship Education and Business Motivation would provide a large stimulus to students in relation to Entrepreneurship Intention.
\end{abstract}

Keyword : Entrepreneurship Education, Business Motivation, Entrepreneurship Intention

\begin{abstract}
Abstrak
Perkembangan kurikulum dan kursus untuk pendidikan kewirausahaan telah terjadi sejak awal tahun 80an. Institusi akademis telah berupaya keras dalam mengembangkan program pendidikan kewirausahaan dan bisnis kecil yang sesuai. Meskipun sejarahnya relatif singkat, pendidikan kewirausahaan telah menjadi area pengajaran yang diakui secara luas dan diakui di Universitas dan sekolah bisnis. Namun, pertanyaan tentang keefektifan program pendidikan kewirausahaan dan bagaimana strategi yang dirancang untuk memaksimalkan keefektifannya, tetap tidak terjawab. Isi dan konteks program pendidikan kewirausahaan di berbagai institusi, daerah dan negara bisa jadi berbeda. Penelitian ini dilakukan di lingkungan Universitas Muhammadiyah Ponorogo dengan populasi mahasiswa Universitas Muhammadiyah Ponorogo. Teknik pengambilan sampel menggunakan metode systematic random sampling, dengan jumlah sampel 50 orang. Data yang diperoleh dianalisa menggunakan alat analisis GSCA. Hasil penelitian menunjukkan bahwa Pendidikan Kewirausahaan dan Motivasi Usaha akan memberikan stimulus yang besar pada mahasiswa dalam kaitannya dengan Minat Berwirausaha.
\end{abstract}

Kata kunci : Pendidikan Kewirausahaan, Motivasi Usaha, Minat Berwirausaha 


\section{A. . PENDAHULUAN}

Ketidakseimbangan lapangan kerja dibandingkan pertumbuhan penduduk usia produktif adalah salah satu penyebab masih terdapat banyak pengangguran di Indonesia. Merujuk pada data BPS pada bulan Agustus tahun 2016 menunjukkan bahwa masih terdapat 16,183 juta orang pengangguran. Dampak dari krisis krisis keuangan global telah tercermin dari berbagai hal, namun yang menarik adalah pengangguran besar - besaran di tingkat lulusan institusi tinggi (Abdullateef, 2017). Akar permasalahan dari tingginya angka pengangguran ditingkat pendidikan tinggi ini antara lain adalah paradigma berfikir lulusan yang masih berorientasi pada jobseeker (Endah, 2013). Selain itu, dampak lain dari krisis tersebut telah menciptakan isu untuk bisnis menjadi kurang efisien (Sivarajah dan Achchuthan, 2013).

Kewirausahaan sangat penting bagi generasi kerja (Acs et al., 1999) dan kemakmuran suatu negara (Kourilsky dan Esfandiari, 1997). Peran pemerintah juga diperlukan dalam mempengaruhi tingkat aktivitas kewirausahaan, membina dan mempromosikan pola pikir kewirausahaan, terutama melalui pendidikan (Rae and Carswell, 2001). Perkembangan kurikulum dan kursus untuk pendidikan kewirausahaan telah terjadi sejak awal tahun 80an. Institusi akademis telah berupaya keras dalam mengembangkan program pendidikan kewirausahaan dan bisnis kecil yang sesuai. Meskipun sejarahnya relatif singkat, pendidikan kewirausahaan telah menjadi area pengajaran yang diakui secara luas dan diakui di Universitas dan sekolah bisnis. Namun, pertanyaan tentang keefektifan program pendidikan kewirausahaan dan bagaimana strategi yang dirancang untuk memaksimalkan keefektifannya, tetap tidak terjawab (Kolvereid, 2014).

Isi dan konteks program pendidikan kewirausahaan di berbagai institusi, daerah dan negara bisa jadi berbeda. Bhardwaj (2014) mengungkapkan bahwa women entrepreneur (WE) di India merasa sulit untuk melatih diri dan membekali diri mereka dengan yang 


\section{JURNAL EKONOMI DAN MANAJEMEN \\ P-ISSN: 2598-9022/ E-ISSN: 2598-9618 \\ Available at:}

http://e-journal.unipma.ac.id/index.php/capital

baru-baru ini perkembangan teknologi dan pasar, karena kendala pada ketersediaan dan sumber daya professional. Oosterbeek, van Praag, dan Ijsselstein (2010) menunjukkan bahwa program pendidikan kewirausahaan tidak berpengaruh pada kemampuan kewirausahaan mahasiswa dan memiliki efek negatif pada minat berwirausaha. Hal yang memungkinkan adalah perbedaan sudut pandang mahasiswa terhadap kurikulum yang diterapkan memberikan efek yang berbeda pula (De Mel, McKenzie, and Woodruff, 2014).

Studi literatur menunjukkan terdapat bias pada temuan yang dilakukan Gerba (2012), bahwa sulit untuk membedakan minat berwirausaha yang timbul dari siswa yang memperoleh pendidikan kewirausahaan dan yang tidak di Ethiopia. Adekiya (2016) juga mendapati fakta bahwa tidak ada bukti empiris mengenai kemampuan program pelatihan kewirausahaan terhadap minat berwiausaha pada lulusan Universitas di Nigeria, walaupun pemerintah setempat telah mewajibkan program ini. Oleh karena itu, penelitian ini akan mencoba mengkaji hubungan antara pendidikan kewirausahaan dan motivasi usaha, khususnya di Universitas Muhammadiyah, berdampak pada tumbuhnya minat berwirausaha pada mahasiswa.

Berdasarkan latar belakang masalah diatas dan untuk memperjelas pokok pembahasan pada penelitian ini, maka masalah dalam penelitian ini dapat dirumuskan sebagai berikut:

1) Apakah Pendidikan Kewirausahaan berpengaruh terhadap Minat Berwirausaha?

2) Apakah Motivasi Usaha berpengaruh terhadap Minat Berwirausaha?

\section{B. TINJAUAN PUSTAKA}

\section{Entrepreneurship}

Ide merupakan faktor penting dalam sebuah entrepreneurship. Hill dan Birkinshaw (2010) mendefinisikan bahwa ide dalam entrepreneurship adalah seperangkat gagasan lengkap yang dimiliki seseorang yaitu terdiri dari mental seseorang yang dapat diakses sesekali untuk dikomersialkan. Sebuah ide tidak harus ditransformasikan atau 


\section{JURNAL EKONOMI DAN MANAJEMEN \\ P-ISSN: 2598-9022/ E-ISSN: 2598-9618 \\ Available at:}

http://e-journal.unipma.ac.id/index.php/capital

dibentuk menjadi sebuah peluang (Farsi, 2014). Gagasan ini dianggap sebagai gagasan belaka sepanjang tidak ada hal yang dilakukan untuk mengembangkan gagasan tersebut dan tidak ada upaya dilakukan untuk meminimalkan ketidakpastian. Oleh karena itu, sebuah ide bukanlah kesempatan dalam entrepreneurship, tapi tidak akan ada kesempatan yang akan muncul tanpa penciptaan sebuah ide (Hayton dan Cholakova, 2012).

Kewirausahaan telah menjadi jauh lebih penting di dunia kontemporer dimana krisis finansial telah terjadi. Kewirausahaan dan inovasi dianggap sebagai alat penting untuk mengatasi tantangan global abad ke-21, hingga struktur yang berkelanjutan 81 pembangunan, untuk menciptakan lapangan kerja baru, untuk mewujudkan pertumbuhan ekonomi yang baru, dan untuk meningkatkan kesejahteraan (Dogan, 2015). Drucker dalam Dogan (2015) menganggap kewiraswastaan sebagai sebuah disiplin. Dari perspektif ini, kewiraswastaan nampak sebagai fakta yang bisa dipelajari. Oleh karena itu, kewiraswastaan memainkan peran penting dalam meningkatkan calon wiraswasta dan mengarahkan mereka menuju pengembangan dan kewirausahaan dengan memberi mereka kombinasi pengetahuan, keterampilan dan kemampuan untuk membangun dan memelihara usaha baru (Dutta, Li dan Merenda, 2011).

Meski interpretasi tentang peran entrepreneurship berbeda, entrepreneurship sering dipandang sebagai fungsi yang melibatkan eksploitasi peluang yang ada di dalam suatu pasar. Eksploitasi semacam itu paling sering dikaitkan dengan alokasi input produktif. Makanya, entrepreneurship sering dikaitkan dengan tindakan kreatif dan inovatif. Audretsch et al. (2006).

$$
\text { Reynolds et al. }
$$
mendefinisikannya sebagai setiap upaya usaha baru atau penciptaan usaha baru, seperti self employment, organisasi bisnis baru atau perluasan yang sudah ada bisnis oleh individu, tim individu atau bisnis mapan. Hindle dan Rushworth (2002) menyatakan bahwa kewiraswastaan didasarkan pada ketersediaan, persepsi dan konversi peluang. Gartner dan Carter (2003) mendefinisikannya sebagai "fenome- 


\section{JURNAL EKONOMI DAN MANAJEMEN \\ P-ISSN: 2598-9022/ E-ISSN: 2598-9618 \\ Available at:}

http://e-journal.unipma.ac.id/index.php/capital

na organisasi dan, lebih spesifik lagi, sebagai sebuah proses pengorganisasian.

\section{Pendidikan Kewirausahaan}

Pendidikan sangat penting untuk menciptakan pemahaman tentang kewiraswastaan, mengembangkan kemampuan kewirausahaan, dan berkontribusi terhadap identitas kewiraswastaan dan budaya pada tingkat individu, kolektif dan sosial (Rae, 2010). Seorang individu, yang menerima pendidikan kewiraswastaan dasar yang menyediakan kompetensi dalam hal administrasi, lebih cenderung terlibat dalam kegiatan kewirausahaan di masa depan (Dutta, Li dan Merenda, 2011).

Pendidikan

kewirausahaan merupakan metode penting yang mendorong kewiraswastaan karena pendidikan 1) memberikan perasaan mandiri dan percaya diri kepada individu, 2) memungkinkan pengakuan pilihan karir alternatif, 3) memperluas cakrawala individu dengan memungkinkan mereka untuk lebih memahami peluang, dan 4) memberikan pengetahuan yang akan digunakan individu dalam mengembangkan peluang bisnis baru. Melalui pendidikan kewiraswastaan yang memadai, seseorang memperoleh keterampilan dan pengetahuan yang dibutuhkan untuk membangun dan mengembangkan bisnis baru (Paco et al., 2015).

Eksternalitas pengetahuan terjadi ketika entrepreneurial insights dari beberapa entrepreneur yang menciptakan peluang untuk entrepreneur lainnya. Meningkatnya pendapatan karena kegiatan ekonomi entrepreneurial semakin menghasilkan penciptaan peluang. (Holcombe, 1998). Mengaitkan entrepreneurship ke dalam kerangka pertumbuhan ekonomi dalam konteks teori pertumbuhan menunjukkan kealamiahan peningkatan pendapatan, eksternalitas pengetahuan dan peranan modal manusia. Proses ini merupakan blackbox dalam arus utama teori pertumbuhan.

Mesin pertumbuhan ekonomi adalah entrepreneurship, bukan teknologi atau investasi dalam human capital. Fokus terhadap entrepreneurship menekankan teori pertumbuhan pada arah institusional dimana pertumbuhan terjadi dan 


\section{JURNAL EKONOMI DAN MANAJEMEN \\ P-ISSN: 2598-9022/ E-ISSN: 2598-9618 \\ Available at:}

http://e-journal.unipma.ac.id/index.php/capital

menjauh dari teori pertumbuhan neoklasik yang fokus pada input proses produksi. Pengaitan entrepreneurship dalam kerangka pertumbuhan ekonomi tidak hanya mengisi kesenjangan entrepreneurship dalam institusi dalam membantu proses pertumbuhan tetapi juga memberikan pencerahan rekomendasi kebijakan ekonomi untuk meningkatkan pertumbuhan ekonomi.

Menurut Ali (2013) menyatakan bahwa pendidikan kewirausahaan merupakan upaya menginternalisasikan jiwa dan mental kewirausahaan baik melalui institusi pendidikan maupun institusi lain seperti lembaga pelatihan, training dan sebagainya. Selanjutnya, menurut Farhangmehr et al., (2016) menyatakan bahwa "the process of transmitting entrepreneurial knowledge and skills to students to help them exploit a business opportunity" (proses transmisi pengetahuan dan keterampilan kewirausahaan kepada siswa untuk membantu mereka dalam memanfaatkan peluang bisnis). Berdasarkan penjelasan para ahli dapat disimpulkan bahwa pendidikan kewirausahaan merupakan upaya yang sistematis dalam rencana membantu memberi pengetahuan berkaitan dengan peluang bisnis yang masih terbuka lebar dan semakin berkembang untuk saat ini.

\section{Motivasi Usaha}

Motivasi didefinisikan oleh Hytti et al., (2010) yaitu pengaruh dari internal dan eksternal untuk mempengaruhi perilaku individu dalam kehidupan yang dijalani. Hal tersebut berarti faktor internal dan eksternal merupakan faktor yang dapat mendorong namun juga faktor penarik untuk seseorang dalam hal ini yaitu menumbuhkan motivasi berwirausaha. Menurut Farhangmehr et al.,(2016) motivasi adalah sebagai kondisi internal yang membangkitkan kita untuk bertindak, mendorong kita mencapai tujuan tertentu, dan membuat kita tetap tertarik dalam kegiatan tertentu. Kemudian menurut Souitaris et al.,(2007) motivasi dapat diartikan sebagai dorongan internal dan eksternal dalam diri seseorang yang diindikasikan dengan adanya; hasrat dan minat; dorongan dan kebutuhan; harapan dan cita-cita; 


\section{JURNAL EKONOMI DAN MANAJEMEN \\ P-ISSN: 2598-9022/ E-ISSN: 2598-9618 \\ Available at:}

http://e-journal.unipma.ac.id/index.php/capital

penghargaan dan penghormatan.

Berdasarkan penjelasan para ahli dapat disimpulkan bahwa motivasi merupakan faktor pendorong dan penarik yang mempengaruhi seseorang untuk melakukan sesuatu dengan tujuan yang sudah ditetapkan.

Darpujianto (2014) menyatakan bahwa terdapat faktor pendorong (Push) dan faktor penarik (Pull) bagi seseorang dalam pilihan atau motivasi dalam berwirausaha. Berikut ini merupakan faktor pendorong untuk seseorang berwirausaha, yaitu:

a. Kemandirian merupakan sikap yang didasarkan pada keinginan seseorang untuk sukses secara pribadi tanpa bantuan dari orang lain.

b. Pengalaman merupakan berbagai kumpulan kejadian masa lalu dalam hal wirausaha yang menjadikan seseorang tampil lebih matang dengan pengalaman yang dimiliki.

c. Dukungan orang tua dan lingkungan merupakan pembawaan situasi yang menjadi latar belakang seseorang untuk memilih profesi sebagai pembisnis. d. Pengambil resiko merupakan sikap berani untuk keluar dari zona nyaman selama ini dan memilih resiko yang lebih tinggi untuk meningkatkan kualitas hidup.

e. Percaya diri merupakan sikap yang membawa seseorang untuk lebih yakin bahwa akan mampu meningkatkan taraf hidup kearah yang lebih baik dengan bermodal pengetahuan dan keahlian yang dimiliki.

Dari berbagai penjelasan tersebut berarti bahwa banyak faktor yang menjadi latar belakang seseorang untuk berwirausaha dan hal tersebut harus mampu dikelola dengan lebih baik agar motivasi yang tinggi tetap terjaga untuk masuk dalam dunia wirausaha.

\section{Minat Berwirausaha}

Minat Berwirausaha adalah cerminan keadaan pikiran dan keinginan seseorang untuk berwiraswasta dan bukan dipekerjakan (Gerba, 2012; Karimi et al., 2016). Minat Berwirausaha bisa diartikan juga sebagai pertunangan atau niat seseorang untuk memulai bisnis yang 


\section{JURNAL EKONOMI DAN MANAJEMEN \\ P-ISSN: 2598-9022/ E-ISSN: 2598-9618 \\ Available at:}

http://e-journal.unipma.ac.id/index.php/capital

baru (Dinis et al., 2013). Namun demikian, (Gibb, 2002) menyatakan bahwa tidak ada definisi yang jelas dan konsisten mengenai istilah Minat Berwirausaha dalam konteks kewirausahaan. Fayolle et. al. (2006) mengusulkan framework berdasarkan TPB (Ajzen, 1991) yang diciptakan untuk menilai perubahan sikap dan pola pikir mahasiswa.

TPB didasarkan pada gagasan bahwa manusia agak rasional dalam pilihan dan niat individu dapat menyebabkan atau mungkin tidak mengarah pada perilaku tertentu (Kuttim et al., 2013). Ada tiga faktor penentu konseptual menurut teori. Pertama, sikap terhadap perilaku menunjukkan tingkat dimana seseorang memiliki kepentingan atau evaluasi atau penilaian yang tidak menguntungkan terhadap perilaku yang bersangkutan. Kedua, norma subjektif berarti tekanan sosial yang dirasakan untuk melakukan atau tidak melakukan perilaku. Ketiga, kontrol perilaku yang dirasakan mengacu pada kemudahan atau kesulitan dalam melakukan perilaku dan diasumsikan untuk mencerminkan pengalaman masa lalu dan juga hambatan yang diharapkan. (Ajzen, 1991, 2005).

\section{METODE PENELITIAN}

Penelitian ini termasuk penelitian eksplanatoris (explanatory research) dengan pendekatan kuantitatif, yaitu penelitian yang berupaya menjelaskan hubungan kausal antara variabelvariabel melalui pengujian hipotesis (Singarimbun dan Effendi, 1995). Pendekatan kuantitatif dilandasi pada suatu asumsi bahwa suatu gejala itu dapat diklasifikasikan, dan hubungan gejala bersifat kausal (sebab akibat) antara variabel atau konstruk melalui pengujian hipotesis (Sugiyono, 2010).

Metode penelitian yang digunakan penelitian menggunakan metode survei, yaitu metode yang digunakan untuk memperoleh informasi melalui permintaan keterangan - keterangan kepada responden dengan menggunakan kuesioner sebagai alat pengumpul data utama (primer). Pada umumnya yang merupakan unit analisis dalam penelitian survei adalah individu (Singarimbun dan Effendi, 1995). Unit analisis dalam penelitian ini adalah mahasiswa 
Fakultas Ekonomi Universitas

Muhammadiyah Ponorogo.

Penelitian ini menganalisis bukti data primer yang dikumpulkan dari mahasiswa Fakultas Ekonomi Universitas Muhammadiyah Ponorogo. Penelitian ini bertempat di Universitas Muhammadiyah Ponorogo, tepatnya di Jl. Budi Utomo No. 10, Ronowijayan, Siman, Kabupaten Ponorogo, Jawa Timur 65111.

Populasi adalah wilayah generalisasi yang terdiri atas objek/subjek yang mempunyai kualitas dan karakteristik tertentu yang ditetapkan oleh peneliti untuk dipelajari dan kemudian ditarik kesimpulannya (Sugiyono, 2010). Populasi dalam penelitian ini adalah seluruh mahasiswa Universitas

Muhammadiyah Ponorogo.

Metode pengambilan sampel yang digunakan adalah metode probability sampling. Probabilitas sampling adalah teknik pengambilan sampel yang memberi peluang atau kesempatan yang sama bagi setiap anggota populasi yang terpilih sebagai sampel penelitian (Sugiyono, 2012: 60). Teknik pengambilan sampel yang digunakan adalah stratified random sampling. Pengambilan sampel dilakukan dengan cara populasi dibagi stratastrata (sub populasi), kemudian pengambilan sampel dilakukan dalam setiap strata. Dalam penelitian ini kriteria sampel adalah :

1) Sampel merupakan mahasiswa Fakultas Ekonomi Universitas Muhammadiyah Ponorogo.

2) Sampel telah melaksanakan program praktek KWU.

Jumlah populasi dalam penelitian ini tidak diketahui, maka untuk menentukan jumlah sampel digunakan rumus Machin and Chambell (1997; 169). Berdasarkan pertimbangan bahwa nilai terendah yang diperkirakan akan diperoleh melalui penelitian ini adalah $\mathrm{r}=0,35$; kemudian $\alpha=0,05 \quad \mathrm{Z} 1-\alpha=1,645$ pada pengukuran dua arah, dan $\beta=$ 0,10 Z1- $\beta=1,645$ maka diperoleh $n$ $($ minimum $)=50$. Sehingga dalam penelitian ini mengambil sampel minimal 50 orang responden. 


\section{JURNAL EKONOMI DAN MANAJEMEN \\ P-ISSN: 2598-9022/ E-ISSN: 2598-9618 \\ Available at:}

http://e-journal.unipma.ac.id/index.php/capital

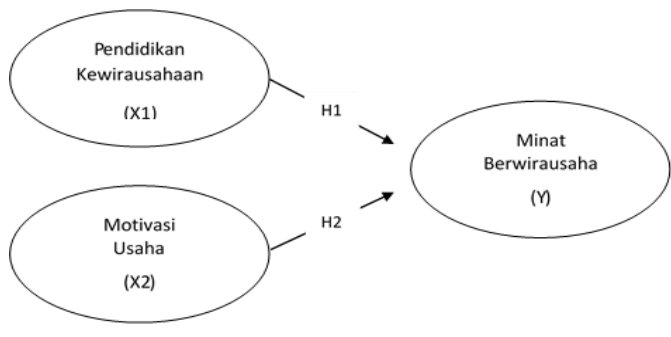

Gambar 1 Model Hipotesis

Gambar di atas menunjukkan model hipotesis dari penelitian ini. Sedangkan rumusan hipotesisnya adalah sebagai berikut:

\begin{tabular}{rlr} 
H1: Pendidikan & \multicolumn{2}{c}{ Kewirausahaan } \\
berpengaruh & positif dan \\
& signifikan terhadap Minat \\
& Berwirausaha.
\end{tabular}

H2: Motivasi Usaha berpengaruh positif dan signifikan terhadap Minat Berwirausaha.

Metode analisis data yang digunakan untuk membuktikan hipotesis yang diajukan dalam penelitian ini menggunakan Generalized Structured Component Analysis (GSCA). GSCA dikembangkan oleh Heungsun Hwang, Hec Montreal, dan Yhoshio Takene pada 2004. Tujuannya adalah menggantikan faktor dalam kombinasi linier dari indikator (variabel manifes) di dalam analisis SEM (Solimun, 2012).Tenehaus (2008) dalam
Solimun (2012) mengatakan bahwa GSCA adalah metode baru SEM berbasis komponen, sangat penting dan dapat digunakan untuk perhitungan skor (bukan skala) dan juga dapat diterapkan pada sampel yang sangat kecil. Di samping itu, GSCA dapat digunakan pada model struktural yang melibatkan variabel dengan indikator refleksif dan atau formatif.

\section{HASIL DAN PEMBAHASAN}

Hasil pengujian validitas untuk item pernyataan yang digunakan dalam mengukur variabel menunjukkan nilai korelasi yang lebih besar dari nilai r-tabel yang ditentukan. Dengan demikian dapat dikatakan bahwa seluruh item pernyataan yang digunakan dalam mengukur variabel tersebut telah menunjukkan tingkat ketepatan yang cukup baik (valid). Sedangkan pengujian reliabilitas seluruh item yang digunakan dalam mengukur variabel dependent dan independent menghasilkan koefisien reliabilitas (cronbach's alpha) diatas 0.6 sehingga dapat dikatakan bahwa instrumen yang digunakan untuk 


\section{JURNAL EKONOMI DAN MANAJEMEN \\ P-ISSN: 2598-9022/ E-ISSN: 2598-9618 \\ Available at:}

http://e-journal.unipma.ac.id/index.php/capital

mengukur seluruh variabel tersebut dinyatakan memiliki reliabilitas yang tinggi. Dengan kata lain instrumen yang digunakan tersebut telah menunjukkan konsistensi pengukuran pada semua respondennya.

Tabel 1 Model FIT GSCA

\begin{tabular}{|c|c|}
\hline \multicolumn{2}{|c|}{ Model Fit } \\
\hline FIT & FIT \\
\hline AFIT & AFIT \\
\hline GFI & GFI \\
\hline SRMR & SRMR \\
\hline NPAR & NPAR \\
\hline
\end{tabular}

FIT menunjukkan varian total dari semua variabel yang dapat dijelaskan oleh model tertentu. Nilai FIT berkisar dari 0 sampai 1. Jadi, model yang terbentuk dapat menjelaskan semua variabel yang ada sebesar 0.788. Keragaman Pendidikan Kewirausahaan, Motivasi Usaha, dan Minat Berwirausaha yang dapat dijelaskan oleh model adalah sebesar $78.8 \%$ dan sisanya $(21.2 \%)$ dapat dijelaskan oleh variabel yang lain. Artinya, jika dilihat dari nilai FIT yang diperoleh, model yang terbentuk dapat dikatakan bagus. Semakin besar nilai FIT yang diperoleh maka model yang ada akan semakin bagus.

Adjusted dari FIT hampir sama dengan FIT. Namun, karena variabel yang mempengaruhi Minat Berwirausaha tidak hanya satu sehingga akan lebih baik apabila interpretasi tentang ketepatan model menggunakan FIT yang sudah terkoreksi atau menggunakan AFIT. Jika dilihat dari nilai AFIT, keragaman Pendidikan Kewirausahaan, Motivasi Usaha, dan Minat Berwirausaha yang dapat dijelaskan oleh model adalah sebesar $80.2 \%$ dan sisanya (19.8\%) dapat dijelaskan oleh variabel yang lain. Artinya, jika dilihat dari nilai AFIT yang diperoleh, model yang terbentuk bagus.

\section{GFI (Unweighted least-squares)} dan SRMR (standardized root mean square residual). Keduanya sebanding dengan perbedaan antara kovarian sampel dan kovarian yang diproduksi oleh pendugaan parameter GSCA. GFI dekat dengan nilai 1 dan nilai-nilai SRMR mendekati 0 dapat diambil sebagai indikasi cocok. Pada permasalahan ini nilai $\mathrm{SRMR}=0,312$ sehingga model yang terbentuk dapat dikatakan telah sesuai. Data stastistik 


\section{JURNAL EKONOMI DAN MANAJEMEN \\ P-ISSN: 2598-9022/ E-ISSN: 2598-9618 \\ Available at:}

http://e-journal.unipma.ac.id/index.php/capital

juga menunjukkan nilai $\mathrm{GFI}=0,846$

maka model dikatakan sesuai.

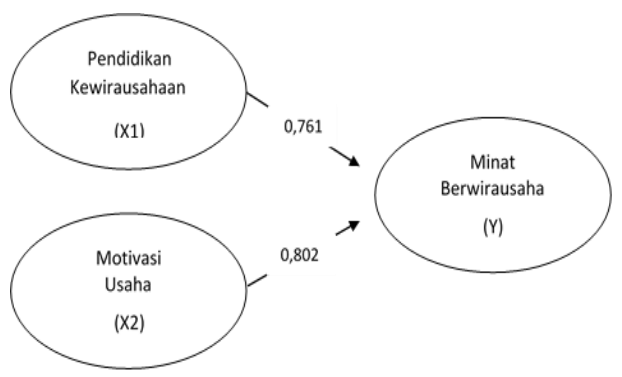

Gambar 2 Model Empiris

$\mathrm{H} 1$ = Pendidikan Kewirausahaan terhadap Minat Berwirausaha. Hipotesis 1 menyatakan bahwa Pendidikan Kewirausahaan berpengaruh signifikan terhadap Minat Berwirausaha. Hasil pengujian model menggunakan GSCA menunjukkan bahwa hasil positif dan signifikan dengan nilai critical rasio sebesar 3.25 dan koefisien jalur sebesar 0.761, sehingga dapat disimpulkan bahwa Pendidikan Kewirausahaan memiliki pengaruh yang signifikan dengan Minat Berwirausaha. Hasil penelitian ini sejalan dengan hasil penelitian Chen (2006), Lorz (2011), Sieger (2011) dan Kuttim (2013).

Beberapa penelitian telah mengkonfirmasi efek positif dari pendidikan kewirausahaan untuk tujuan kewirausahaan, namun ada juga penelitian yang menyatakan sebaliknya (Lorz, 2011). Hal ini sejalan dengan penelitian (Kuttim et $a l ., 2013)$ yang menyatakan hubungan antara program pendidikan kewirausahaan dengan maksud menumbuhkan minat berwirausaha siswa dengan menggunakan TPB.

$$
\mathrm{H} 2 \text { = Motivasi Usaha terhadap }
$$
Minat Berwirausaha. Hipotesis menyatakan bahwa Motivasi Usaha berpengaruh signifikan terhadap Minat Berwirausaha. Hasil pengujian memperoleh bukti empiris bahwa $\mathrm{H} 2$ berpengaruh positif dan signifikan. Artinya, semakin tinggi Motivasi Usaha semakin tinggi pula Minat Berwirausaha. Hasil pengujian model menggunakan GSCA menunjukkan bahwa hasil pengujian berpengaruh positif dan signifikan dengan nilai critial ratio sebesar 3.19 dan koefisien jalur sebesar 0.802 . Hal ini konsisten dengan hasil penelitian Chen (2006), Branback (2007), dan Gerba (2012).

Brannback et. al. (2007) menyatakan bahwa diperlukan replikasi dalam meneliti penelitian niat untuk memajukan pengetahuan ilmiah di daerah tersebut. Temuan 


\section{JURNAL EKONOMI DAN MANAJEMEN \\ P-ISSN: 2598-9022/ E-ISSN: 2598-9618 \\ Available at:}

http://e-journal.unipma.ac.id/index.php/capital

penelitian Gerba (2012) menunjukkan bahwa niat adalah prediktor penting dari perilaku yang direncanakan selanjutnya. Peneliti lain (Pruett et al., 2009; Krueger et al., 2000) juga berpendapat pentingnya mempelajari fenomena kewirausahaan sebelum terjadi.

Tabel 2 Pengujian Structural Model

\begin{tabular}{|c|c|c|c|}
\hline \multicolumn{3}{|c|}{ Path Coefficients } \\
\hline $\begin{array}{c}\text { Pendidikan } \\
\text { Kewirausahaan-> Minat } \\
\text { Berwirausaha }\end{array}$ & 0.761 & 0.233 & $3.25^{*}$ \\
\hline $\begin{array}{c}\text { Motivasi Usaha-> Minat } \\
\text { Berwirausaha }\end{array}$ & 0.802 & 0.238 & $3.19^{*}$ \\
\hline
\end{tabular}

\section{E. SIMPULAN}

Dari hasil penelitan dengan judul Pengaruh Pendidikan Kewirausahaan dan Motivasi Usaha terhadap Minat Berwirausaha (Studi pada Mahasiswa Fakultas Ekonomi Universitas Muhammadiyah Ponorogo) menggunakan alat analisis GSCA dapat disimpulkan beberapa hal, yaitu:

1) Semua variabel yang diuji dalam model mempunyai hubungan yang positif. Dapat dikatakan bahwa jika salah satu variabel mengalami kenaikan, maka memberikan pengaruh kenaikan juga pada variabel yang lain.

2) Hasil penelitian menunjukkan bahwa Pendidikan Kewirausahaan dan Motivasi Usaha akan memberikan stimulus yang besar pada mahasiswa dalam kaitannya dengan Minat Berwirausaha.

Berdasarkan hasil penelitian, saran yang perlu dipertimbangkan yakni:

1) Peneliti selanjutnya dapat melakukan pengumpulan data dengan menggunakan penggabungan instrumen lain selain kuesioner, seperti wawancara mendalam dengan responden maupun dengan pihak penyelenggara pendidikan kewirausahaan sehingga dapat diperoleh informasi dan gambaran variabel dan hubungannya secara lebih jelas.

2) Berdasarkan keterbatasan penelitian di atas, peneliti selanjutnya disarankan untuk mengambil obyek penelitian dan jumlah sampel yang berbeda untuk mengkaji model secara lebih 
mendalam, serta diharapkan akan memperoleh hasil yang maksimal.

\section{DAFTAR RUJUKAN}

Acs, Z.J., Carlsson, B. and Karlsson, C. (1999), "The linkages among entrepreneurship, SMEs and the Macro economy", in Acs, Z.J., Carlsson, B. and Karlsson, C. (Eds), Entrepreneurship, Small and Medium-Sized Entreprises and the Macro Economy, Cambridge University Press, Cambridge.

Adekiya, Adewale. (2016). Entrepreneurship intention among students. The antecedent role of culture and entrepreneurship training and development, The International Journal of Management Education, Vol. 14 pp. 116 132.

Ajzen, I. (2005). Attitudes, Personality and Behaviour. New York: Open University Press.

Annamária Heuer Lars Kolvereid, (2014),"Education in entrepreneurship and the Theory of Planned Behaviour", European Journal of Training and Development, Vol. 38 Iss 6 pp. 506 - 523 Permanent link to this document: http://dx.doi.org/10.1108/EJTD -02-2013-0019.

Bechard, J.-P. and Toulouse, J.M. (1998), "Validation of the didactic model for the analysis of training objectives in entrepreneurship", Journal of Business Venturing, Vol. 13 No. 4, pp. 317-332.

BPS. (2017). Keadaan Angkatan Kerja di Indonesia. Badan Pusat Statistik. Jakarta.

Brannback, M., Carsrud, A., Elfvin, J., Kickul, J. and Krueger, N. (2007), "Why replicate entrepreneurial intentionality studies? Prospects, perils and academic reality", available at: www.entrepreneurship.fiu.edu/ downloads/publications/papers.

Broto Rauth Bhardwaj, (2014),"Impact of education and training on performance of women entrepreneurs", Journal of Entrepreneurship in Emerging Economies, Vol. 6 Iss 1 pp. $38-52$ Permanent link to this document:

http://dx.doi.org/10.1108/JEEE-052013-0014.

Dinis, A., Paco, A. F., Ferreira, J., Raposo, M. and Rodrigues, R. G. (2013), 'Psychological characteristics and entrepreneurial intentions among secondary students', Education+ Training, vol. 55, no. $8 / 9$, pp. 3-3.

Dogan, Ebru. 2015. The effect of entrepreneurship education on entrepreneurial intentions of university students in turkey. Disertasi : Universitas IstanbulTurki.

Dutta, Dev K., Jun Li and Michael Merenda. (2011), Fostering 
entrepreneurship: Impact of specialization and diversity in education. International Entrepreneurship Management Journal, Vol.7, Iss.2, pp.163179.

Endah, Eny. (2013). Pengaruh Kepribadian Dan Lingkungan Terhadap Intensi Berwirausaha Pada Usia Dewasa Awal. Buletin Ekonomi, Vol. 11, No. 1, hal 1-86.

Fayolle, A., Gailly, B. \& LassasClerc, N. (2006). Assessing the impact of entrepreneurship education programmes: a new methodology. Journal of European Industrial Training, 30(9), 701-720. http://dx.doi.org/10.1108/03090 590610715022.

Gerba, D. T. (2012), 'The context of entrepreneurship education in Ethiopian universities', Management Research Review, vol. 35, no. 3/4, pp. 225-244.

Gibb, A. (2002). In pursuit of a new 'enterprise' and 'entrepreneurship' paradigm for learning: creative destruction, new values, new ways of doing things and new combinations of knowledge.

International Journal of Management Reviews, 4(3), 233-269. http://dx.doi.org/10.1111/14682370.00086.

Hamid Mahmood Gelaidan Aliyu Olayemi Abdullateef, (2017)," Entrepreneurial intentions of business students in Malaysia: the role of self-confidence, educational and relation support ", Journal of Small Business and Enterprise Development, Vol. 24 Iss pp. - Permanent link to this document: http://dx.doi.org/10.1108/JSBE D-06-2016-0078.

Hayton, J.C. and Cholakova, M. (2012), "The role of affect in the creation and intentional pursuit of entrepreneurial ideas", Entrepreneurship Theory and Practice, Vol. 36 No. 1, pp. 41-68.

Hill, S.A. and Birkinshaw, J.M. (2010), "Idea sets: conceptualizing and measuring a new unit of analysis in entrepreneurship research", Organizational Research Methods, Vol. 13 No. 1, pp. 85113.

Hindle, K. and Cutting, N. (2002), "Can applied entrepreneurship education enhance job satisfaction and financial performance? An empirical investigation within the Australian pharmacy profession", Journal of Small Business Management, Vol. 40 No. 2, pp. 162-167.

Johannisson, B. (1991), "University training for entrepreneurship: a Swedish approach", Entrepreneurship and Regional Development, Vol. 3 No. 1, pp. 67-82.

Karimi, S., Biemans, H. J. A., Lans, T., Chizari, M. and Mulder, M. 


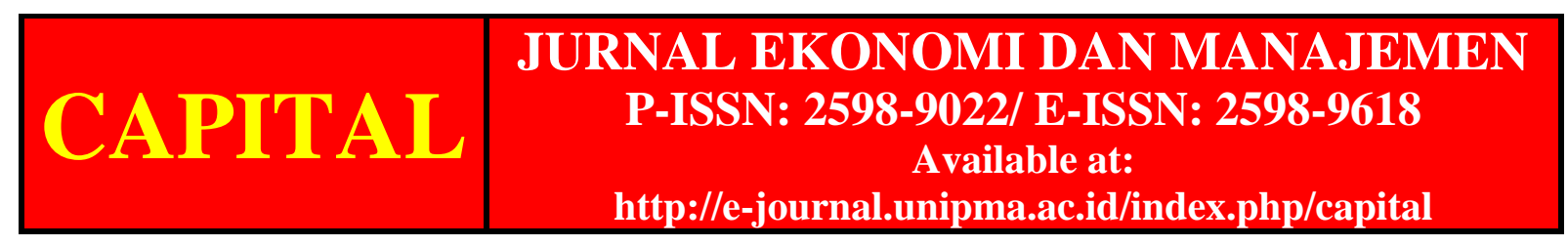

(2016), 'The impact of entrepreneurship education: A study of Iranian students' entrepreneurial intentions and opportunity identification', Journal of Small Business Management, vol. 54, no. 1, pp. 187-209.

Kourilsky, M.L. and Esfandiari, M.

(1997), "Entrepreneurship education and lower socioeconomic black youth: an empirical investigation", The Urban Review, Vol. 29 No. 3, pp. 205-215.

Kuttim, Merle. Et al,. (2013). "Entrepreneurship education at university level and students entrepreneurial intentions". Procedia - Social and Behavioral Sciences 110 ( 2014 ),pp. $658-668$.

Linan, F. and Chen, Y.W. (2006), "Testing the entrepreneurial intention model on a twocountry sample", Working Paper No. 06/07, Department of Business Economics, Universitate Autonoma de Barcelona, Barcelona, July.

Lorz, M. (2011). The Impact of Entrepreneurship Education on Entrepreneurial Intention. Dissertation of the University of St. Gallen, School of Management, Economics, Law, Social Sciences and International Affairs. http://edudoc.ch/record/107284/ files/zu13059.pdf (27.06.2013).
McKenzie, D., \& Woodruff, C. (2014). What are we learning from business training and entrepreneurship evaluations around the developing world. World Bank Research Observer, 29 (1).

Oosterbeek, H., van Praag, M., \& Ijsselstein, A. (2010). The impact of entrepreneurship education on entrepreneurship skills and motivation. European Economic Review, 54 (3).

Paco, Arminda do et. al. (2015), "Entrepreneurial Intentions: Is Education Enough?", International Entrepreneurship and Management Journal, Vol.11, Iss.1, pp.57-75.

Pruett, M., Shinnar, R., Toney, B., Llopis, F. and Fox, J. (2009), "Explaining entrepreneurial intentions of university students: a cross-cultural study", International Journal of Entrepreneurial Behavior \& Research, Vol. 15 No. 6, pp. 571-94.

Rae, D. and Carswell, M. (2001), "Towards a conceptual understanding of entrepreneurial learning", Journal of Small Business and Enterprise Development, Vol. 8 No. 2, pp. 150-158.

Rae, David (2010), "Universities and enterprise education: responding to the challenges of the new era", Journal of Small Business and Enterprise 
Development, Vol.17, Iss.4, pp.591-606.

Roya Molaei Mohammad Reza Zali Mohhammad Hasan Mobaraki Jahngir Yadollahi Farsi, (2014),"The impact of entrepreneurial ideas and cognitive style on students entrepreneurial intention", Journal of Entrepreneurship in Emerging Economies, Vol. 6 Iss 2 pp. 140 - 162 Permanent link to this document: http://dx.doi.org/10.1108/JEEE09-2013-0021.

Sieger, P., Fueglistaller, U., Zellweger, T. (2011). Entrepreneurial Intentions and Activities of Students Across the World. International Report of the GUESSS Project 2011. St.

Gallen. http://www.guesssurvey.org/PD F/2011/GUESSS_INT_2011_FI NAL.pdf (05.02.2013).

Sivarajah, K. and Achchuthan, S. (2013), 'Entrepreneurial Intention among undergraduates: Review of literature', European Journal of Business and Management, vol. 5, no. 5, pp. 172-186. 